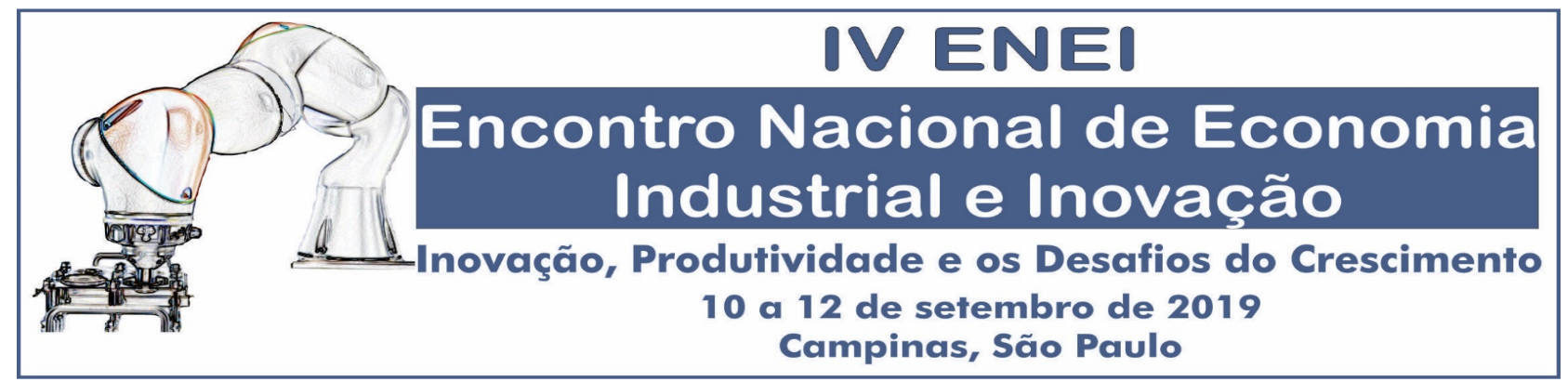

\title{
O PROCESSO INOVATIVO E O DESENVOLVIMENTO DO LESTE ASIÁTICO: UMA ABORDAGEM INSTITUCIONAL-EVOLUCIONÁRIA ${ }^{1}$
}

\author{
Dienifer Regina Fortes Storti ${ }^{2}$ \\ Angel Maitê Bobato ${ }^{3}$ \\ Julio Eduardo Rohenkohl ${ }^{4}$ \\ Igor Castellano da Silva ${ }^{5}$
}

\begin{abstract}
Resumo
O artigo teve como objetivo discutir o papel do processo inovativo no desenvolvimento do Leste Asiático através de uma abordagem institucional- evolucionária. Em um primeiro momento, foi realizada uma abordagem teórica acerca das concepções das teorias econômicas institucional e evolucionária para entender a relação entre os processos de inovação e desenvolvimento. Em um segundo momento, foi realizada uma revisão geopolítica do processo histórico que ocasionou à ascensão econômica do Leste Asiático ainda no século XX. E por fim, buscou-se discutir de que forma os aspectos geradores de inovações e elas próprias foram importantes para o desenvolvimento da região do Leste Asiático. Constatou-se que apesar do processo geopolítico ser determinante para entender o desenvolvimento econômico, como Arrighi (1997) propõe, a compreensão do processo inovativo, caracterizado pela acentuada acumulação de capacitações e conhecimento ocorrida na região, é essencial para analisar o desenvolvimento e ascensão do Leste Asiático.
\end{abstract}

Palavras-Chave: Sistema de Inovação; Instituições; Leste Asiático; Geografia da Inovação.

Classificação JEL: O14, O30, O43.

\section{THE ROLE OF THE INNOVATIVE EAST ASIA DEVELOPMENT PROCESS: AN INSTITUTIONAL-EVOLUTIONARY APPROACH}

\begin{abstract}
The paper aimed to discuss the role of the innovative process in East Asian development through an institutional-evolutionary approach. At first, a theoretical approach was taken on the conceptions of the institutional and evolutionary economic theories to understand the relation between the processes of innovation and development. In a second moment, a geopolitical review of the historical process that led to the economic rise of East Asia in the twentieth century was carried out. And finally, we sought to discuss how the aspects that generated innovations and themselves were important for the development of the East Asian region. Although the geopolitical process is crucial to understand economic development, as Arrighi (1997) proposes, the understanding of the innovative process,

\footnotetext{
${ }^{1}$ O presente trabalho foi realizado com apoio da Coordenação de Aperfeiçoamento de Pessoal de Nível Superior Brasil (CAPES) - Código de Financiamento 001.

${ }^{2}$ Mestranda do Programa de Pós-Graduação em Economia e Desenvolvimento da Universidade Federal de Santa Maria.

${ }^{3}$ Mestranda do Programa de Pós-Graduação em Economia e Desenvolvimento da Universidade Federal de Santa Maria.

${ }^{4}$ Professor do Departamento de Economia e Relações Internacionais da Universidade Federal de Santa Maria.

${ }^{5}$ Professor do Departamento de Economia e Relações Internacionais da Universidade Federal de Santa Maria.
} 


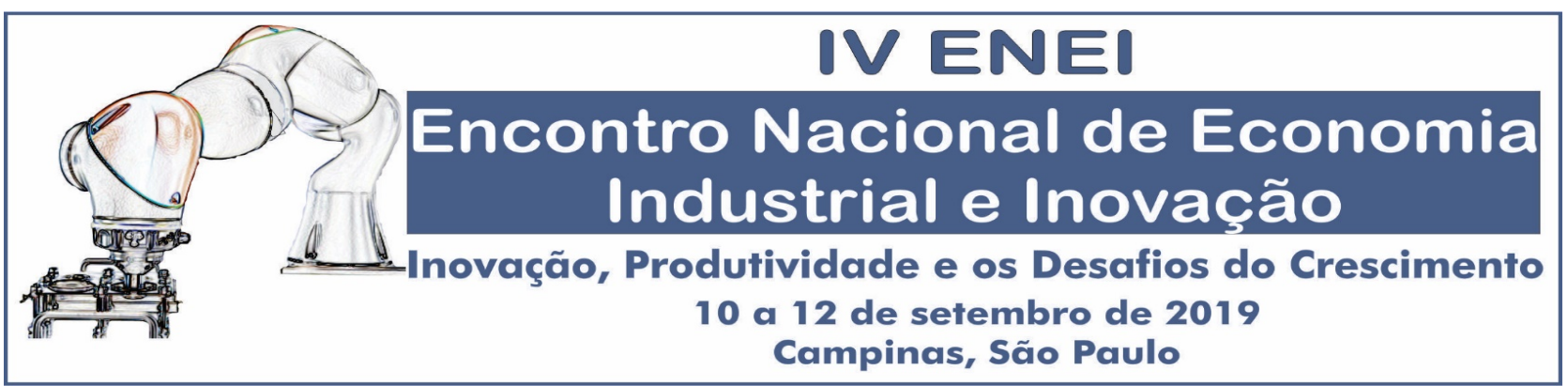

characterized by the accrued accumulation of skills and knowledge occurred in the region, is essential to analyze the development and rise of the East Asia.

Key-words: Innovation System; Institutions; East Asia; Geography of Innovation;

JEL Classification: O14, O30, O43.

Área ABEIN: Área 5 - Inovação e mudança técnica, organizacional e institucional: 5.5 Mudanças técnicas, organizações e instituições. 


\section{INTRODUÇÃO}

Nos países em desenvolvimento, o século XX foi marcado pela formulação e execução de diversos planos de industrialização e desenvolvimento econômico. A ascensão do leste asiático, impulsionada por um acelerado processo de crescimento japonês que ficou conhecido como milagre econômico, em contraste com a dificuldade apresentada por países latinoamericanos em dar continuidade em seus próprios processos de desenvolvimento, exigiram da teoria econômica uma nova base conceitual e metodológica que permitisse uma melhor compreensão dos processos.

Os rígidos pressupostos ligados ao comportamento maximizador dos agentes econômicos e à noção de equilíbrio, somados à visão estática do que Nelson e Winter (2005) chamaram de economia ortodoxa, mostraram-se inadequados para tratar do caráter complexo e dinâmico das relações internacionais e do desenvolvimento econômico. Elementos como inovação, heterogeneidade dos agentes, presença de incerteza, existência de instituições e políticas de Estado foram incorporadas, então, por economistas evolucionários e institucionalistas, que despenderam maior esforço em entender a dinâmica evolutiva dos processos do que em analisar cenários estáticos.

O caráter endógeno das inovações incorporado por Schumpeter (1985), e a dinâmica dos processos de geração e difusão inovativa trabalhada por autores neo-schumpeterianos permitiram ampliar a visão do papel do progresso tecnológico no desenvolvimento econômico. Guimarães (2010), em seu estudo, diferencia capacitação tecnológica e modernização, argumentando que enquanto o primeiro representa um processo pelo qual há um acúmulo de capacitações que proporcionam uma diminuição do hiato tecnológico do país em desenvolvimento em relação aos países desenvolvidos, o segundo consiste na simples elevação do nível de tecnologia utilizada. Ainda segundo o autor, para que ocorra o desenvolvimento econômico, é preciso que se passe da simples capacidade de produção para a capacidade de inovação e, para tanto, não basta que se tenha acesso às tecnologias, é preciso domina-las.

Nesse aspecto, Borrás e Edquist (2003) afirmam que enxergar o processo inovativo sob uma visão sistêmica e analisa-lo dentro de seu contexto histórico, social e institucional é primordial para entender as políticas adotadas e trajetórias de desenvolvimento percorridas por cada país. Nesse âmbito, para que ocorra a geração e difusão de inovação se faz necessária a existência de uma série de elementos como as firmas, instituições, universidades e institutos de P\&D que devem interagir entre si de forma articulada. Além disso, destaca-se o papel do Estado tanto da formulação de políticas industriais e de inovação, quanto na atuação em funções de regulação e de incentivo às atividades inovativas. De tal forma que não se pode separar o processo inovativo dos processos econômicos, sociais e políticos e tampouco analisa-los fora de seu contexto geográfico e histórico.

Os estudos de Giovanni Arrighi como "O Longo Século XX" e a "Ilusão do desenvolvimento" evidenciam aspectos político-históricos que foram fundamentais para a evolução do capitalismo na sociedade. Entretanto, o autor não aborda nesses estudos a importância das inovações para o desenvolvimento das nações. Em uma passagem de sua obra "O longo Século XX" de 1996, o autor aborda que o intuito de seus estudos é verificar de que forma ocorre as fases de mudanças contínuas e descontínuas do capitalismo, deixando de lado "as inovações em determinadas indústrias ou em determinadas economias nacionais" (ARRIGHI, 1996, p. 9). Por outro lado, Campanário (2002) ressalta que com os processos de Globalização, analisar atualmente as economias capitalistas sem abordar a importância do progresso técnico tornou-se algo praticamente impossível, considerando que a tecnologia é algo essencial para o desenvolvimento e dinâmica das sociedades.

A crise de superacumulação que os Estados Unidos, atual hegemonia capitalista, parece enfrentar desde 1970, proporcionou condições favoráveis para a ascensão do Leste Asiático 
como "nova oficina do mundo" (ARRIGHI, 1996), devido a isso, além do processo- histórico, de que forma as inovações auxiliaram no desenvolvimento dessa região? Sendo assim, o objetivo deste artigo é discutir o papel do processo inovativo no desenvolvimento do Leste Asiático através de uma abordagem institucional-evolucionária.

O trabalho conta com um total de quatro seções, além desta introdução. A segunda seção apresenta algumas concepções teóricas da economia institucional e evolucionária a respeito de paradigmas tecnológicos, geografia da inovação e sistemas de inovação. A seção 3 traz algumas noções de geopolítica do leste asiático. A quarta seção discute o desenvolvimento econômico do leste asiático com base nos conceitos e noções vistos das seções anteriores. Por fim, a quinta seção apresenta as considerações finais do estudo.

\section{INOVAÇÃO E DESENVOLVIMENTO: ALGUMAS CONCEPÇÕES DAS TEORIAS ECONÔMICAS INSTITUCIONAL E EVOLUCIONÁRIA}

Esta secção está dividida em duas subseções. A primeira aborda a noção de paradigmas tecnológicos e relaciona os processos de mudança de paradigma tecnológico às oportunidades de desenvolvimento econômico. Enquanto a segunda, discorre a respeito dos conceitos de sistemas de inovação e geografia da inovação.

\subsection{OS PARADIGMAS TECNOLÓGICOS E O DESENVOLVIMENTO ECONÔMICO}

Para chegar ao conceito de paradigma tecnológico, Dosi (2006) partiu da ideia de paradigma científico formulada por Thomas Kuhn. O paradigma científico de Kuhn é definido como um modelo ou padrão no qual se expressam problemas relevantes e serve como uma delimitação que norteia o desenvolvimento da ciência. Assim, o paradigma tecnológico seria um modelo ou padrão de solução de problemas tecnológicos selecionados, com base em princípios selecionados. Segundo La Rovere (2006), o paradigma tecnológico pode estar configurado tanto por um objeto (por exemplo, um circuito integrado), quanto por um "conjunto heurístico" para a resolução de problemas.

As trajetórias tecnológicas seriam, segundo Dosi (2006), atividades "normais" de resolução de problemas com base em determinado paradigma tecnológico. La Rovere (2006) afirma que a trajetória tecnológica compreende o caminho de desenvolvimento tecnológico tomado pelas firmas sob um paradigma tecnológico e considerando suas escolhas passadas. Dessa forma, as escolhas presentes das firmas dependem de suas escolhas passadas e a trajetória tecnológica é caracterizada por um processo de path-dependence.

Assim, as trajetórias tecnológicas compreendem possibilidades de escolhas delimitadas pelo próprio paradigma tecnológico que, por sua vez, é caracterizado por sua capacidade de exclusão. Em outras palavras, pode haver diversas trajetórias tecnológicas simultâneas, mas um paradigma tecnológico. De forma que quando ocorre a mudança do paradigma tecnológico, modifica-se o escopo no qual estão localizadas as trajetórias, e é preciso repensar as atividades de resolução de problemas praticamente do princípio. O desenvolvimento tecnológico pode ser entendido, então, através de dois processos, um mais geral responsável por fornecer as bases e a direção do fenômeno evolutivo (isto é, o paradigma tecnológico) e outro mais específico caracterizado pela seleção de caminhos a serem percorridos (isto é, as trajetórias tecnológicas) (DOSI, 2006).

Conforme enfatiza Dosi (2006), é importante ressaltar que as forças econômicas, institucionais, políticas e sociais exercem grande influência no estabelecimento de paradigmas e trajetórias tecnológicas. Isso ocorre devido à grande presença de incertezas que dificulta a comparação dos diferentes paradigmas e trajetórias ex-ante, assim como a mensuração de seus possíveis benefícios. Por esse motivo, é comum que a direção do desenvolvimento tecnológico 
seja traçada pelo poder público, como foi o caso dos programas militar e espacial no período da Guerra Fria. Nesse aspecto, Borrás e Edquist (2003) argumentam que as políticas ligadas à inovação estão normalmente relacionadas a objetivos mais amplos estabelecidos no âmbito político de cada país, que os autores chamam de objetivos finais. Os objetivos finais podem ser objetivos econômicos, ambientais, sociais, relacionados à saúde ou à defesa nacional, dentre outros.

Entender a importância dos fatores políticos e institucionais também é fundamental para compreender por que certas nações foram capazes de aproveitar as oportunidades advindas das mudanças de paradigmas tecnológicos, enquanto outras não. Segundo Perez (2001), as oportunidades de desenvolvimento econômico surgem na medida em que ocorrem as revoluções tecnológicas, mas elas só podem ser aproveitadas na medida em que os países desenvolvam capacitações para isso. Nesse sentido, a autora argumenta que o processo de "destruição criadora" que ocorre durante as revoluções tecnológicas vai além da esfera econômica, abrangendo também as instituições e políticas.

Segundo Cimoli et al. (2007), todos os países que conseguiram realizar catching-up envolveram em seus processos de desenvolvimento um conjunto de medidas políticas voltadas à indústria e tecnologia e um processo de "construção institucional". De forma que, ao longo da história, o sucesso ou insucesso dos países em aproveitar as oportunidades de mudança de paradigma tecnológico estiveram fortemente ligadas à sua capacidade de combinar diferentes mixes de instituições e políticas. Nas palavras dos autores, a mudança de paradigma tecnológico compreende um processo pelo qual:

[...] vantagens comparativas se transformam em profecias autocumpridas de um conjunto bem-sucedido de ações institucionais e estratégias privadas: ex post, o sucesso econômico e tecnológico torna "ótimo" do ponto de vista do economista aquilo que ex ante constituía um sonho político (CIMOLI et al., 2007, p. 75).

Cimoli et al. (2007) afirmam que as políticas e as instituições atuam principalmente nos mecanismos de geração e acumulação de conhecimento, como, por exemplo, através da regulamentação de direitos de propriedade intelectual e na coordenação das relações entre os diferentes indivíduos e organizações, influenciando inclusive nos processos de seleção nos ambientes concorrenciais de mercado. Dessa forma, as políticas e instituições exercem papel fundamental no processo de aprendizagem e adaptação enfatizados por Perez (2001) como condições essenciais para que os países consigam aproveitar as oportunidades que surgem durante a mudança de paradigma tecnológico.

Cabe ressaltar que não apenas as macro instituições são importantes no processo, mas também as instituições internas às firmas. Segundo Baptista (2000), as firmas não recebem um pacote dado de oportunidades, cada firma reage de uma forma aos sinais enviados pelo mercado, criando seu próprio leque de oportunidades de acordo com sua área de atuação, os ativos que já possuem e suas capacitações dinâmicas e rotinas de aprendizado. Os ativos que uma firma possui e o conhecimento por ela acumulado podem atuar como limitadores de sua flexibilidade, tendo em vista que uma mudança de trajetória tecnológica poderia implicar na perda de valor de ativos que possui, colocando a empresa em path-dependence ou até mesmo lock in. As capacitações dinâmicas e rotinas criativas e de aprendizado estão justamente atreladas à capacidade das firmas inovarem e aproveitarem novas oportunidade e, portanto, à sua eficiência dinâmica.

Para explicar a janela de oportunidade advinda de uma mudança de paradigma tecnológico, Perez (2001) utiliza a ideia de ciclo de vida do produto, em que a vida do produto é representada por um total de cinco fases. A primeira é a mais repleta de incertezas e é 
caracterizada pelo uso de tecnologias mais intensivas em mão-de-obra qualificada e, portanto, costumam ocorrer em países desenvolvidos. Com o passar do tempo, conforme o produto vai sendo padronizado, as tecnologias vão amadurecendo e os processos se tornam cada vez mais mecânicos e automatizados, a produção passa a ser transferida para países menos desenvolvidos. Embora a fase de maturação do produto seja a que compreende as menores possibilidades de ganhos advindos do surgimento de inovações, ela ainda assim, representa para os países menos desenvolvidos uma oportunidade para o melhoramento da estrutura de industrialização e da infraestrutura básica e para o desenvolvimento das capacidades de aprendizagem.

Em períodos de mudança de paradigma tecnológico, como visto anteriormente, as atividades de resolução de problemas precisam ser repensadas praticamente do zero, pois a base na qual se sustentam as trajetórias tecnológicas está sendo modificada. De tal forma que em períodos de troca de paradigma tecnológico, as experiências e os conhecimentos acumulados têm seu valor reduzido, podendo atuar inclusive como empecilhos à adaptação ao novo paradigma. Como a revolução tecnológica pode levar anos, muitos produtos e indústrias estarão situados na fase I ou V e o período se caracteriza como uma janela de oportunidade para os países em desenvolvimento. Isso porque, ao se tornarem responsáveis pela produção referente às indústrias que estão na fase $\mathrm{V}$, existe a possibilidade de que reúnam as capacitações necessárias para se inserirem em indústrias na fase I. Como a fase I do ciclo de vida dos produtos apresenta as maiores possibilidades em termos de surgimento e ganhos com inovações, o país se torna capaz de obter o catching-up (PEREZ, 2001).

\subsection{OS SISTEMAS DE INOVAÇÃO E A GEOGRAFIA DA INOVAÇÃO}

Para compreender a forma como o ambiente econômico, político e institucional exerce influência no processo inovativo, especialmente em cenários de grandes mudanças tecnológicas, é preciso, em primeiro lugar entender a natureza social e sistêmica das inovações. Segundo Rosenberg (2006), a necessidade de considerar o processo inovativo dentro do contexto histórico e geográfico no qual ele está inserido não é uma questão recente dentro da economia. Segundo o autor, Marx já atentava para a impossibilidade de compreender os processos de mudança tecnológica através da análise de inovações tomadas isoladamente, argumentando que as mudanças tecnológicas compreendem processos contínuos de acumulação de conhecimento e, mesmo que as inovações sejam atribuídas a indivíduos ou firmas específicas, elas só puderam surgir em decorrência do amplo contexto no qual estavam inseridas.

A relevância do caráter cumulativo e contextual da geração e difusão inovativa também foi documentada na origem da economia institucional. Resgatando os trabalhos de Veblen, Pessali e Fernandez (2006) afirmam que o pensador americano entendia a tecnologia como uma aplicação sistemática do conhecimento acumulado organizado, incapaz de evoluir separadamente dos costumes, hábitos, tradições, valores e pensamentos comuns de uma sociedade, definidos pelo autor como instituições. Nesse aspecto, os autores admitem que as instituições podem atuar tanto dificultando o progresso tecnológico, como no caso da existência de instituições inadequadas e extremamente rígidas, quanto podem também facilitar o processo.

A ideia de analisar a geração e difusão inovativa através da abordagem de sistemas de inovação surge justamente como forma de trazer para a análise o amplo contexto no qual esses processos estão inserindo, conferindo um caráter interdisciplinar ao agregar ideias de áreas como economia, história e sociologia. Um sistema é caracterizado pela existência de componentes que se relacionam uns com os outros. Quando se trata de sistemas de inovação, os principais componentes são as organizações e as instituições, que interagem por meio de 
processos complexos e não lineares. Por organizações, entende-se estruturas formais criadas conscientemente e que possuem propósitos explícitos, são os "jogadores do jogo". Já as instituições são, conjuntos de hábitos comuns, normas, rotinas, dentre outros elementos que regulam as interações entre os diferentes agentes, chamadas por Douglas North de "regras do jogo" (EDQUIST, 2010).

As dimensões de um sistema de inovação podem estar ou não atreladas a limites geográficos, no caso de estarem, as abordagens mais comuns são: sistemas nacionais de inovação, sistemas regionais de inovação e sistemas locais de inovação. Quando não estão, são normalmente trabalhadas através das noções de sistemas setoriais de inovação e sistemas tecnológicos. O conceito de sistemas tecnológicos foi desenvolvido inicialmente por Carlsson e Stankiewitz (1991), definindo como uma rede de interação entre agentes que geram, difundem e utilizam tecnologias em uma determinada área industrial específica sob uma infraestrutura institucional particular ou sob um conjunto de infraestruturas. De forma que os limites de um sistema tecnológico podem não ser coincidentes aos limites geográficos nacionais, já que a diferenciação é feita de acordo com as áreas industriais-tecnológicas e não de acordo com as demarcações geográficas.

Entretanto, mesmo quando se trata de sistemas de inovação não limitados por fronteiras espaciais, há teorias que fornecem indícios de que a proximidade pode atuar de forma positiva na geração e difusão inovativa. Segundo Garcia (2017), a geografia da inovação está relacionada a todas as possibilidades advindas da proximidade das atividades produtivas. Vale ressaltar que a proximidade aqui tratada não é a simplesmente espacial, mas sim, uma proximidade que pode ser entendida através de cinco dimensões: geográfica, social, organizacional, institucional e cognitiva. O ponto central é a percepção de que o conhecimento tácito, advindo das experiências dos agentes econômicos e que não pode ser integralmente codificado, pode ser transferido de maneira mais fluida quando os agentes econômicos possuem similaridades e/ou vínculos prévios. Essa proximidade em suas diferentes dimensões, além de contribuir para os processos de geração e difusão inovativas, é capaz de criar, em tal sistema, vantagens competitivas em relação aos agentes que não pertencem a ele.

Uma visão mais ampla e não limitada às fronteiras geográficas, e a consideração de diferentes dimensões de proximidade se mostram fundamentais em um cenário de globalização, onde ocorrem processos de expansão das fronteiras produtivas e estreitamento dos vínculos entre países e regiões. Segundo Da Silva e Egler (2004), nesse cenário, existe a possibilidade de países se conectarem por meio de redes, ocasionando o surgimento de novos espaços de inovação, caracterizados por novas modalidades de acumulação e regulamentação, o que exige que as relações entre territórios e inovações sejam repensadas, dando origem a uma geografia da inovação.

Perez (2001) afirma que esse cenário representa o estabelecimento de um novo paradigma caracterizado, dentre outras coisas, pelas tecnologias de comunicação e informação e pela estruturação em redes flexíveis. Nesse aspecto, o Estado nacional aparece como líder estratégico, responsável por conciliar os níveis subnacionais e supranacionais. Love e Roper (2015), por sua vez, atentam para a importância das rotinas criativas das firmas para a acumulação de conhecimento gerado através das relações estabelecidas com outras firmas e organizações estrangeiras.

Nessa perspectiva, a existência de processos de geração e difusão inovativas em um âmbito supranacional facilitados por determinado grau de proximidade em uma ou mais dimensões e caracterizado pela existência de organizações e instituições que se correlacionam, permite pensar na ideia de um sistema de inovação além das fronteiras nacionais e que pode, também, não estar limitado à um único setor da indústria. 


\section{ASPECTOS GEOPOLÍTICOS DA ASCENSÃO DO LESTE ASIÁTICO}

O capitalismo histórico pode ser entendido como sistema mundo (ARRIGHI, 1996). Para esta compreensão, Arrighi (1996) utiliza-se de conceitos desenvolvidos por Karl Marx, como capital-dinheiro e capital-mercadoria, formulando assim a concepção de ciclo sistêmico de acumulação. Dessa forma, estes ciclos seriam as combinações de fases de expansão material, ou fases de mudanças continuas, e a expansão financeira, chamada também de fase descontínua de mudanças do capitalismo. A expansão financeira, caracteriza-se como sendo a fase de maturidade do capitalismo, ou seja, quando a economia capitalista está alcançando seus limites, mostrando a necessidade do surgimento de um novo ciclo de acumulação. Os países que conseguem internalizar os transbordamentos do ciclo vigente, e através de estratégias e transformações necessárias no cenário da economia mundial, sobressaem tornando-se a nova hegemonia do capitalismo

Através dessa concepção de ciclos sistêmicos de acumulação, Arrighi (1996) analisa ao longo do século XV e nos posteriores, quatro ciclos sistêmicos nos quais o capitalismo evoluiu. Esses ciclos são o genovês (do século XV ao início do século XVII), holandês (engloba o final do século XVI até as penúltimas décadas do século XVIII), britânico (metade do século XIX e permanece até início do século XX), e por fim, tem-se o ciclo sistêmico de acumulação norte americano, que tem como início o final do século XIX, entretanto, diferente dos outros ciclos este ainda não chegou ao fim, ou pelo menos, ainda não houve a ascensão de outro país que tenha assumido a hegemonia do capitalismo mundial.

Devido a isso, esta pesquisa utiliza-se de aspectos do ciclo norte americano para evidenciar a política- histórica da ascensão dos países do Leste Asiático no século XX, para que dessa maneira entenda-se como houve a transição sistêmica do Leste Asiático para grandes potências cada vez mais dominantes na economia capitalista.

Arrighi (1996) destaca que o ciclo sistêmico de acumulação que passará assumir se desenvolve ainda sob o ciclo vigente, e isso deixará de ocorrer somente quando o novo ciclo obtiver ganhos com a expansão material de toda a economia, criando assim condições para que se torne a nova hegemonia da economia capitalista. Além disso, os ciclos sistêmicos de acumulação enfrentam durante seu percurso, a crise chamada de sinalizadora, onde os recursos crescentes obtidos com o comércio e produção são realocados para atividades financeiras, como especulação e financeirização. Esses fatos são sintomas da instalação de uma crise sistêmica no ciclo vigente. O deslocamento de recursos pode estar causando a extinção da expansão material, fazendo com que o ciclo esteja em seu fim, ou entrando em uma crise denominada terminal, possibilitando que novas hegemonias se destaquem no capitalismo mundial (ARRIGHI, 1996).

E foi isso que ocorreu com o ciclo norte americano, que superou fatores característicos como políticas e instituições do regime britânico, durante a maturidade/ expansão financeira do ciclo britânico vigente na época, que se encontrava em sua crise terminal. Dessa forma, havia sinais que mudanças estavam para ocorrer no capitalismo mundial.

E realmente houve mudanças, os Estados Unidos têm sua ascensão tornando-se a nova hegemonia do capitalismo mundial, possuía fatores como tamanho, acesso ao mar e poderio militar-industrial que o tornava cada vez mais poderoso, contribuindo para a formação de alianças com nações e amedrontando outras. Tais características permitiram aos Estados Unidos ser o primeiro ciclo a internalizar os custos de proteção, produção e também os de transação. Contribuindo assim para a consolidação da economia capitalista mundial através de sistemas de mercados nacionais e com a presença de firmas transnacionais (ARRIGHI, 1996).

$\mathrm{O}$ ciclo norte americano fomentou as inovações tecnológicas e a competividade, elevando assim a economia a um novo patamar, além disso, os Estados Unidos durante a Primeira Guerra Mundial tornaram-se o maior fornecedor da indústria bélica do mundo, conseguindo transformar o período de gastos em ganhos de receita com a guerra. Dessa forma, 
os Estados Unidos conseguiram acumular uma elevada reserva de divisas. E após a Crise de 1929 e a Segunda Guerra mundial, dois momentos em que o Estados Unidos e o resto do mundo enfrentaram mudanças políticas e econômicas, o país norte americano tornou-se a mais poderosa liderança econômica mundial. Nesse período há a criação de instituições importantes para a manutenção dessa condição americana, que foi o Acordo de Bretton Woods, que levou a criação da Organização das Nações Unidas (ONU), o Banco Mundial e o Fundo Monetário Internacional (FMI) (ARRIGHI, 1996; RIBEIRO, 2009).

Para Costa (2014), o pós-segunda guerra mundial transformou os Estados Unidos na maior hegemonia do mundo, sendo que na época uma das principais preocupações do país era conter as expansões comunistas, que estavam ocorrendo. Segundo Castells (2000), os Estados Unidos estavam preocupados principalmente com o risco da Ásia ser tomada pelos comunistas, esse fator se tornou importante elemento geopolítico para o Leste Asiático.

Apesar dos Estados Unidos conseguirem consolidar-se economicamente após a Segunda Guerra Mundial, isso não ocorreu com outros país, devido ao fato de terem perdido a guerra e estarem destruídos. Dessa forma, os Estados Unidos desenvolveram um plano de reconstrução, denominado Plano Marshall, que tinha como intuito ajudar a reconstruir economicamente os países devastados pela Segunda guerra mundial.

O Japão que havia perdido e estava devastado após essa guerra, de acordo com Arrighi (1997), reergueu-se através da Guerra da Coréia, também citada como o Plano Marshall do Japão. De maior rival, os Estados Unidos passaram a ser o maior aliado japonês, suas estratégias geopolíticas proporcionaram ao Japão a possibilidade de se reconstruir sem ter que arcar com custos de proteção (militares), passando a preocupar-se somente com os lucros (RIBEIRO, 2009). Isso ocorreu porque os Estados Unidos deram ao Japão, proteção doméstica e acesso total de seus mercados e suprimentos da economia mundial. O Japão foi impulsionado pelos ganhos da Guerra, e também pelo interesse dos Estados Unidos em manter o poder econômico e regional do país, se tornando um instrumento para os norte-americanos, para o país era conveniente manter o Japão próximo, para realizar a ligação entre o poder de aquisição dos Estados Unidos e a mão-de- obra de baixo custo (ARRIGHI, 1997).

Arrighi (1996) ressalta que o Leste Asiático apresentou melhorias nos níveis de renda per capita desde a Segunda Guerra Mundial, aproximando-se de nações chamadas de "núcleo orgânico" da economia, que eram nações ricas como a América do Norte, Europa Ocidental, Austrália e Nova Zelândia, estas economias apresentavam os maiores padrões de riqueza da época. Dentre os países do Leste Asiático, o Japão se sobressaiu, para Arrighi (1997) o milagre econômico do Leste Asiático foi fundamentalmente um milagre japonês, e somente depois esse milagre se estenderia para o resto da região.

Dessa forma, a ascensão do Leste Asiático, conforme Arrighi $(1996,1997)$ se deu através de três estágios, sendo que o primeiro foi a expansão japonesa, como já destacado, que em quarenta anos alcançou e superou o padrão de renda das regiões que possuíam uma renda per capita de aproximadamente sete vezes maiores que a sua. $\mathrm{O}$ segundo foi quando essa equiparação de renda passa a ocorrer também em outros país, isso ocorre na década de 1970, quando o grupo dos quatro (Taiwan, Hong Kong, Cingapura e Coréia do Sul) começam a se aproximar do Japão, em relação ao desenvolvimento. E o último estágio, foi quando a expansão atingiu a região do Leste Asiático como um todo, de acordo com o autor isso ocorreu na década de 1980, mas vale destacar que nessa década alguns países que haviam apresentado crescimento em 1970, apresentaram declínio. Entretanto, países como Itália, e os países do Leste Asiático não sentiram os problemas dessa década, que ficou conhecida como a década perdida, e que resultou no declínio de muitas economias.

O milagre econômico Leste Asiático então caracteriza-se como a redução entre as diferenças de renda dos países mais ricos com aqueles que ainda estavam se desenvolvendo 
(ARRIGHI, 1997). Assim, para Arrighi (1996) há evidências que o Leste Asiático ascendeu em meio à crise econômica mundial.

Essa crise econômica mundial apresentou alguns aspectos, como a intensificação da concorrência entre as interempresas, ocasionando o aumento exacerbado dos salários que o Japão e a economia capitalista como um todo tiveram que enfrentar. A intensificação dentro dos países e os aumentos dos custos devido ao aumento dos salários ocasionou a queda em 1971 do padrão vigente de taxas de câmbio fixas em padrão dólar - ouro. Isso acirrou mais a concorrência entre os países, sendo que foi mais intensa no leste asiático, como o Japão, que utilizou-se da desvalorização cambial de sua moeda para conseguir vantagens competitivas para se desenvolver (ARRIGHI, 1997).

Para Arrighi (1997) outro aspecto da crise é a diversificação espacial das atividades que ocorreu nos países para conter os custos, principalmente de mão de obra, com intuito de minimizar a redução dos lucros que resultou do aumento da concorrência entre as empresas e que ocasionou a elevação dos salários. Essa elevação de salários e a queda do câmbio fixo, levaram as empresas japonesas e alemãs a desenvolverem empresas transnacionais.

Com o desenvolvimento dessas empresas transnacionais, percebe-se a transferência de produção para outros países, dessa forma, pode-se dizer que houve a transferência de regiões ricas para as pobres, devido também a oferta de mão de obra barata. Isso funcionou como equiparação entre os países na década de 1970.

Entretanto isso durou até a crise do petróleo, nesse período as empresas financeiras dos Estados Unidos e alguns países da Europa Ocidental, abarrotaram o mercado com oferta de crédito barato para as economias em desenvolvimento, além de ter aumentado a quantidade de investimento estrangeiro direto. Arrighi (1997) discute que esses fatos reduziram as desigualdades de renda entre os países, mas que a duração disso foi muito pequena, visto que, no começo da década de 1980, essas formas de investimento dos mais ricos para os pobres diminuíram drasticamente, principalmente porque o Banco Central dos Estados Unidos elevou suas taxas de juros para atrair investimento, ou seja, aumentar sua liquidez com intuito de controlar de alguma forma sua dívida interna, que não parava de aumentar. Devido a isso, a redução das diferenças entre os países parou tão rapidamente como teve início, não tinha mais como isso ser financiado pelos países ricos.

Em quanto a maioria das economias enfrentavam esses aspectos da crise econômica mundial, o Leste Asiático vivenciava sua ascensão através de acumulação de capital. Esses fatos contribuíram para o Japão adentrar no mercado com as transnacionais e intensificar seu sistema de subcontratação de múltiplas camadas. Dessa maneira, a forma de produção do Leste Asiático e sua posição manufatureira o tornaram promissor para ascender durante esse caos que a economia mundial estava passando. De acordo com Arrighi (1997) e Jesus (2006), a competição e os lucros do sistema de subcontratação de múltiplas camadas que se expandiu regionalmente é considerada como a base mais importante nas décadas de 1970 e 1980, para o milagre econômico Leste Asiático.

No final da década de 1960, os Estados Unidos começam a apresentar problemas de cunho financeiro, o surgimento desses problemas foi em decorrência de grandes dispêndios fiscais que o Estado de Bem-Estar Social e de Guerra dos Estados Unidos estava tendo naquele momento. Dessa forma, iniciava-se a crise do regime norte-americano de acumulação, ou ainda a crise de superacumulação (ARRIGHI, 1996).

Essa crise da década no final de 1960 e início de 1970, apresentaram fatores como a expansão transnacionalmente do capital japonês, e a subcontratação de múltiplas camadas de empresas comerciais, permitiu a descentralização de atividades produtivas do Leste Asiático, acessando todas as camadas inferiores de subcontratações (ARRIGHI, 1997).

A ascensão do leste asiático, como evidenciado começou com o Japão, entretanto o grupo dos quatro, também denominado de Tigres Asiáticos tiveram uma forte expansão a partir 
de 1970 regida pela expansão financeira dessa década, Arrighi (1997) destaca que Cingapura auxiliou no desenvolvimento do Mercado Asiático do Dólar. Hong Kong tornou-se o terceiro país com mais representantes de bancos estrangeiros do mundo, tornando-se assim o maior centro financeiro da economia mundial. Taiwan passou a acumular reservas estrangeiras, e a Coréia do Sul ainda desfrutava dos créditos baratos ofertados na década de 1980 e apresentou uma elevação nos seus investimentos estrangeiros diretos, dessa forma esse país configuravase nessa época como o maior investidor estrangeiro direto do Leste Asiático. Tais características possibilitaram aos Tigres asiáticos se tornarem os maiores investidores da Ásia, estando à frente do Japão e dos Estados Unidos. As características que tornaram o Leste asiático importante região de acumulação de capital foram "os avanços nas hierarquias de valor agregado e financeiras da economia capitalista mundial” (ARRIGHI, 1996, p. 101).

Arrighi (1996) discute que os Tigres Asiáticos e o Japão juntaram suas empresas a fim de utilizar os recursos de mão- de -obra após as elevações que houve nos salários, dessa maneira uma quantidade significativa de mão-de -obra relativamente barata foi inserida nas redes de comércio e nas produções dos países do Leste- Asiático, esses fatores contribuíram para manter a ascensão dessa região.

Outra questão que Arrighi (1997) pontua em sua análise como importante fator para impulsionar a expansão econômica do Leste Asiático tem relação com a diáspora chinesa, que eclodiu quando a China teve sua economia ligada novamente ao comércio e dessa forma aumentou sua acumulação de capital. Entretanto, a China possuía uma elevada quantidade de recursos humanos, detinha o controle da força de trabalho, mas continuava com níveis baixos de renda. Para o autor, a Coréia do Sul era a que possuía características para se sobressair no Leste Asiático, entretanto, Arrighi (1996) afirma que o diferencial da China para ascender é que o seu desenvolvimento está ocorrendo através do mercado. Ouriques (2011) pontua que o sucesso da nação chinesa se deve a utilização de tecnologias que não poupam mão-de-obra, sendo que a China é a grande detentora desse fator, logo, a China consegue utilizar suas vantagens de reservatório de trabalhadores para conseguir associar o capital estrangeiro com suas empresas que fornecem essa mão-de-obra e seu governo, obtendo assim sucesso no capitalismo mundial.

Entretanto, há controvérsias nessa perspectiva, Robinson (2010) defende que o que possibilitou a China sobressair no mercado foi a exploração intensiva de seus trabalhadores, para este autor esse processo chinês está longe de algo que apresente igualdade ou respeito com o povo da China, para o autor esse crescimento ainda não pode ser caracterizado como um desenvolvimento sustentável. O que é de comum acordo, é que há uma discussão se a ascensão da China será capaz de modificar o cenário capitalista mundial, ou seja, se está se tornará a nova hegemonia capitalista, dando início a um novo ciclo sistêmico de acumulação. Várias são as teorias em relação a essa questão, entretanto, este não é o objetivo deste artigo.

\section{O PROCESSO INOVATIVO E A ASCENSÃO DO LESTE ASIÁTICO}

A ascensão do leste asiático se deu em um contexto geopolítico caracterizado pela hegemonia americana e sob um paradigma tecnológico centrado nas tecnologias de comunicação e informação e estruturado em redes produtivas flexíveis. Segundo La Rovere (2006), o novo paradigma tecnológico estabelecido foi especialmente benéfico aos países asiáticos, como Coreia do Sul e Taiwan, que souberam aproveitar a janela de oportunidades para se especializarem na produção de componentes e equipamentos voltados para tais tecnologias.

Segundo Dosi (2006), durante a história é possível perceber uma estreita relação entre os paradigmas tecnológicos e os padrões de desenvolvimento social e produtivo, de forma que com o surgimento de uma revolução tecnológica, é comum que haja modificações nas estruturas 
social-produtivas. Nesse aspecto, a transição entre o padrão de produção taylorista-fordista para um padrão de produção toyotista ilustra bem a questão. Garcia (1998) afirma que a transição para toyotismo consistiu em uma reestruturação produtiva condizente com o novo paradigma tecnológico que se estabelecia, caracterizado por uma base técnica cada vez mais informatizada e automatizada, o surgimento de novos materiais como fibras ópticas, supercondutores e chips, e novos processos envolvendo aspectos como mecânica fina e a eletronização dos produtos.

O modelo de produção toyotista representou, acima de tudo, uma inovação organizacional. Houve um aumento nas atividades de terceirização e cooperação entre as firmas, a produção em massa deu lugar a um padrão produtivo just-in-time e o ambiente interno à firma passou a ser descrito através da utilização de termos como polivalência e tecnologia de grupo, além de um crescente envolvimento dos próprios operários das firmas em atividades de resolução de problemas (GARCIA, 1998).

No leste asiático, as características toytistas puderam ser vistas através desde o sistema japonês de subcontratação de múltiplas camadas abordado por Arrighi $(1996 ; 1997)$ até as estratégias de investimento de firmas japonesas que implicava em uma maior qualificação da mão-de-obra do chão de fábrica, abordadas por Queiroz (2006). Como destacado por Arrighi (1997), embora o sistema de subcontratação de múltiplas camadas tenha se iniciado abrangendo unicamente empresas japonesas, com o aumento de agregação de valor nos produtos japoneses e o desenvolvimento do respectivo país, tal sistema foi expandido para os demais países do leste asiático, atingindo primeiramente os quatro tigres asiáticos e posteriormente os demais países como China e Vietnã.

O processo pelo qual o Japão se utilizou do apoio concedido pelos Estados Unidos para ascender nas cadeias produtivas para posições de maior valor agregado e em setores ligados às tecnologias de comunicação e informação atreladas ao novo paradigma tecnológico representa um caso bem-sucedido da dinâmica descrita por Perez (2001) envolvendo mudanças de paradigmas tecnológicos e os ciclos de vida dos produtos.

Além disso, nota-se que não apenas o Japão utilizou a janela de oportunidades gerada pela mudança de paradigma tecnológico para realizar o catching-up pelo processo descrito pela autora, mas também os quatro tigres asiáticos que aproveitaram as estruturas industriais construídas com a transferência de atividades produtivas de menor valor agregado, vindas do japão, para eles próprios desenvolverem os atributos necessários para passarem da simples capacidade de produção à capacidade de inovação. Utilizando a terminologia de Guimarães (2010), o que pôde ser visto no leste asiático não foi um mero processo de modernização das estruturas produtivas, mas sim uma capacitação tecnológica.

Embora, os países asiáticos tenham pontos divergentes em suas trajetórias de desenvolvimento, alguns pontos em comum merecem atenção. O primeiro deles é a presença ativa do Estado na criação de políticas industriais e inovativas, na coordenação de reformas institucionais, incluindo os sistemas de ensino, e na proteção e apoio às indústrias nacionais. Em relação a esse último aspecto, Queiroz (2006) chamou a proteção oferecida pelos governos asiáticos de "proteção para o aprendizado", pois segundo o autor, diferentemente do que foi visto na América Latina, as políticas protecionistas adotadas pelos países do leste asiático serviram para a acumulação de capacitações e a construção de vantagens comparativas por parte das firmas e indústrias nacionais.

Os Estados nacionais de países como Japão, Coréia e Taiwan, buscaram transformar a estrutura econômica desses países como intuito de dar prioridades às indústrias de alta tecnologia, para isso, a necessidade de proteção de determinados setores é importante, pois para a expansão da capacitação tecnológica é necessário ter aprendizado para fomentar as inovações. Grazziotin (2013) ainda destaca que cartéis foram desenvolvidos para a proteção de tais setores. Logo após essas indústrias mostraram que conseguiram atingir a capacidade de acumulação de tecnologia através desses fatores dos Estados e principalmente através da aprendizagem. 
Ainda no que tange o Estado, a formulação de políticas industriais e de inovação que permitissem a criação de Sistemas Nacionais de Inovação se mostraram de suma importância no processo. Segundo Borras e Edquist (2003), o governo taiwanês, de caráter desenvolvimentista, traçou como objetivos prioritários o desenvolvimento de infraestrutura, investimento em educação e desregulamentação de mercados, para isso foram desenvolvidas políticas de relacionadas à realização de atividades de $\mathrm{P} \& \mathrm{D}$ em instituições públicas e divulgação dos resultados ao setor privado.

Pereira e Dathein (2016) ressaltam que a Coréia do Sul teve sua transformação industrial inicial através da base agrária, e o Estado visava a industrialização como a principal forma de desenvolvimento econômico do país. Os autores destacam que a política industrial na Coréia do Sul é constituída como uma instituição nacional desenvolvimentista, ou seja, é papel central do Estado fomentar atividade industrial no país, para dessa forma obter desenvolvimento econômico de longo prazo. O país se tornou um dos maiores subsidiários de empresas de setores estratégicos que possuíam aptidão para inovação, financiando assim pesquisa e desenvolvimento (P\&D) em tais setores. Os autores ainda destacam que o país exigia bom desempenho das empresas, somente assim, seu setor de inovação seria subsidiado. Dessa forma, a Coréia do Sul se transformou cada vez mais em uma importante economia, centrada no aprendizado tecnológico e por aptidões tecnológicas.

No Japão, as políticas industriais e de inovação eram de responsabilidade do Ministério do Comércio Internacional e Indústria (MITI), um dos órgãos com maior poder dentro da estrutura. Este órgão planejou e organizou toda a política industrial japonesa, inclusive o planejamento das Keiretsu (conglomerados de empresas), e focavam nas grandes empresas que eram intensivas em capital. O Estado fomentava a assimilação de tecnologia através de produtos importados, além disso, o país conseguiu conciliar os interesses do Estado com as empresas que detinham grandes capitais, com intuito de ter acesso constantemente a processos tecnológicos e também a parcelas maiores de mercado (SALERNO; MIRANDA, 2010).

$\mathrm{Na}$ China, coube ao Conselho de Estado a formulação das diretrizes conhecidas como Oitavo e Nono Planos Quinquenais que orientaram os processos de industrialização e desenvolvimento nacionais. A política industrial chinesa foi seletiva e orientada, priorizando setores considerados estratégicos, dentre eles estavam os setores de alta tecnologia e capitalintensivos. Os objetivos principais estavam ligados à superação de entraves estruturais e gargalos produtivos e o desenvolvimento de vantagens competitivas. $\mathrm{O}$ Estado atuou de forma intervencionista, articulando uma combinação de políticas e ações nas áreas de comércio exterior, atração de investimento externo direto e desenvolvimento tecnológico (MASIERO e COELHO, 2014).

A respeito das instituições internas às firmas, outro ponto em comum entre os países do leste asiático é a forte presença de rotinas dinâmicas e criativas em suas empresas e indústrias. Segundo Bell e Pavitt (1995), as firmas asiáticas perceberam que capacidades de adaptação e geração de mudança eram importantes não apenas para adquirir vantagens competitivas, como também para mantê-las. O que pôde ser observado nas estratégias adotadas pelas firmas japonesas com foco em inovações e com a realização de incrementos inovativos contínuos. E mais especificamente, nas melhorias de engenharia realizadas pela Coreia do Sul nos setores de petroquímica e siderurgia, além dos esforços inovativos realizados na indústria automobilística.

Além disso, as capacidades dinâmicas de aprendizagem, somadas aos relativamente fracos mecanismos de proteção de direitos de propriedade intelectual, forneceram aos países do leste asiático, especialmente o Japão, à possibilidade da realização de engenharia reversa. Segundo Bell e Pavitt (1995), tal prática permitiu não apenas a acumulação de conhecimento e capacidades de aprendizagem, uma maior rapidez e difusão de novas tecnologias e processos de imitação criativa, mas também uma melhor organização e uma maior integração das diferentes atividades internas às firmas. Em outras palavras, os processos de engenharia reversa 
permitiram também melhorias organizacionais e institucionais. Na Coreia do Sul, a proximidade em suas diferentes dimensões, permitiu o surgimento de economias de aglomeração através dos chaebols, que consistiam em conglomerados produtivos.

Segundo Queiroz (2006), as limitações encontradas pelos países do leste asiático relativos a deficiências de demanda interna foram contornadas por estratégias em âmbito macro e microeconômico voltadas à exportação. Também nesse aspecto, as rotinas criativas fornecem as capacidades necessárias para que a inserção no comércio internacional permita processos de learning-by-trading, como descrito por Love e Roper (2015). Entretanto, a acumulação de conhecimento externo nos países do leste asiático não se dá unicamente através da inserção internacional das firmas das cadeias produtivas, mas também através do envio de engenheiros e administradores ao exterior.

Segundo Bell e Pavitt (1995), os indivíduos enviados para estudar no exterior, retornam aos seus países de origem com maiores habilidades para acessar redes internacionais de informações e exercer atividades de resolução de problemas, ou seja, atividades ligadas à inovação. Em um paradigma tecnológico caracterizado pelas tecnologias de comunicação e informação e pela flexibilidade das redes produtivas, inovativas e de conhecimento, habilidades assim são fundamentais. Além disso, o contato com sistemas de aprendizagem estrangeiros aumenta, o que Garcia (2017) chamou de proximidade cognitiva, dos cientistas asiáticos, melhorando suas aptidões para enfrentar processos de mudanças em paradigmas e trajetórias tecnológicas e, consequentemente, as rotinas criativas das firmas. Dessa forma, são menores as chances de que as firmas e indústrias se vejam em processos de lock-in.

\section{CONSIDERAÇÕES FINAIS}

Após a Segunda Guerra Mundial, os Estados Unidos passaram a ser a maior potência econômica capitalista do mundo, entretanto na década de 1970, em meio à crise econômica mundial que atingiu as nações, o país norte-americano tem sua hegemonia enfraquecida. Nesse contexto, começava o milagre econômico do Leste Asiático, puxado pela ascensão japonesa. Devido a isso, o objetivo desta pesquisa foi verificar o papel das inovações sobre o desenvolvimento do Leste Asiático, ou seja, verificar se os processos inovativos foram relevantes para o desenvolvimento das nações da região.

Percebeu-se que as inovações contribuíram para a ascensão dos países do Leste Asiático, principalmente para àquelas nações que souberam aproveitar das janelas de oportunidades originadas pelo novo paradigma relacionada às tecnologias de comunicação e informação. Verificou-se também a existência de uma relação estreita entre os paradigmas tecnológicos e os padrões de desenvolvimento social e produtivo. Devido a esse fato, o novo paradigma tecnológico trouxe consigo não apenas o surgimento de novos materiais e produtos que revolucionaram o mercado, mas também novas estruturas sociais e produtivas.

Além disso, verificou-se a forte presença do Estado em fomentar as políticas industriais e inovativas nos países, o que proporcionou a criação de sistemas nacionais de inovação que contribuíram para a geração e difusão inovativa. Em relação às instituições internas às firmas, destaca-se a importância da acumulação de conhecimento propiciada pelo aperfeiçoamento das rotinas dinâmicas e criativas e por processos de aprendizagem como o learning-by-trading.

\section{REFERÊNCIAS}

ARRIGHI, G A Ascensão do Leste Asiático e a Desarticulação do Sistema Política Mundial. Tempo, Rio de Janeiro, v. 1, n. 2, p.132-150, dez. 1996. 
ARRIGHI, G. A Ilusão do Desenvolvimento. Petrópolis: Editora Vozes, 1997. p. 53 - 134.

ARRIGHI, G. O Longo Século XX: dinheiro, poder e as origens de nosso tempo. 7. ed. Rio de Janeiro: Editora Unesp, 1996.

BAPTISTA, M. Política Industrial, Ed. da Unicamp, Campinas, 2000.

BELL, Martin, et al. The development of technological capabilities. Trade, technology and international competitiveness, 1995, 22.4831: 69-101.

BORRÁS, S.; EDQUIST, C. (2013). The choice of innovation policy instruments. Technological forecasting and social change, 80(8), 1513-1522.

CAMPANÁRIO, M. A. Tecnologia, Inovação e Sociedade. Organización de Estados Iberoaméricanos, 2002. Disponível em: <https://www.oei.es/historico/salactsi/milton.htm>. Acesso em: 10 dez. 2018.

CARLSSON, Benny; STANKIEWICZ, Rikard. On the nature, function and composition of technological systems. Journal of evolutionary economics, 1991, 1.2: 93-118.

CASTELLS, Manuel. Fim de milênio. São Paulo, Paz e Terra, 1999.

CIMOLI, Mario, et al. Instituições e políticas moldando o desenvolvimento industrial: uma nota introdutória. Revista brasileira de inovação, 2007, 6.1: 55-85.

COSTA, L. B. Ascensão da China: Uma Análise do Contexto Internacional e o Processo de Crescimento Econômico Chinês. 98f. Monografia (Graduação em Relações Internacionais) Departamento de Economia e Relações Internacionais, Universidade Federal de Santa Catarina. Santa Catarina, 2014.

DA SILVA, Valdenildo Pedro; EGLER, Cláudio AG. A inovação em tempos de globalização: uma aproximação. Scripta Nova: revista electrónica de geografía y ciencias sociales, 2004, 8.33: 170 .

DOSI, Giovanni. Mudança técnica e transformação industrial: a teoria e uma aplicação à indústria dos semicondutores. Editora Unicamp, 2006.

EDQUIST, Charles. Systems of innovation perspectives and challenges. African Journal of Science, Technology, Innovation and Development, 2010, 2.3: 14-45.

GARCIA, J. D. Negociação coletiva de trabalho. São Paulo em Perspectiva, 1998.

GARCIA, R. Geografia da Inovação. In: Rapini, M.S; Silva, L.A.. Albuquerque, E.A. (org). Economia da Ciência, Tecnologia e Inovação - Fundamentos Teóricos e a Economia Global. Rio de Janeiro: E-papers, 2017.

GRAZZIOTIN, H. A. Explicando as "rigidezes flexíveis do Leste Asiático- resenha de Ha-Joon Chang. Revista Ciência do Trabalho, v.1, n.1, 2013.

GUIMARÃES, F. C. D. M. S. (2010). A política de incentivo à inovação: inovação, desenvolvimento econômico e política tecnológica. Parcerias Estratégicas, 5(9), 121-128.

JESUS, M. C. R. Desenvolvimento econômico no Leste e no Sudeste Asiático, na segunda metade do século XX. 2006. Ensaios FEE, Porto Alegre, v. 27, n. 1, p. 179-206, maio 2006.

LA ROVERE, Renata Lebre. Paradigmas e trajetórias tecnológicas. Economia da Inovação Tecnológica. São Paulo: Hucitec: Ordem dos Economistas do Brasil, 2006.

LOVE, J. H.; ROPER, S. SME innovation, exporting and growth: A review of existing evidence. International small business journal, v. 33, n. 1, p. 28-48, 2015. 
MASIERO, Gilmar; COELHO, Diego Bonaldo. A política industrial chinesa como determinante de sua estratégia going global. Brazilian Journal of Political Economy/Revista de Economia Política, 2014, 34.1.

NELSON, R. R.; WINTER, S. G. (2005). Uma teoria evolucionária da mudança econômica. Editora Unicamp.

OURIQUES, H. R. A Ascensão do Leste Asiático: uma síntese sobre a interpretação de Giovanni Arrighi. Teoria e Pesquisa: Revista de Ciência Política, São Carlos, v. 20, n. 2, p.149165, jul. 2011.

PEREIRA, A. J.; DATHEIN, R. Política Industrial Como Instituição Desenvolvimentista: Uma Crítica Ao "Novo Desenvolvimentismo" Baseada Nas Experiências De Brasil E Coreia Do Sul. Revista Economia Contemporânea. Rio de Janeiro, v. 20, n. 1, p. 28-57., 2016.

PEREZ, Carlota. Cambio tecnológico y oportunidades de desarrollo como blanco móvil. 2001.

PESSALI, Huáscar; FERNÁNDEZ, Ramón. A tecnologia na perspectiva da economia institucional. Economia da inovação tecnológica. São Paulo: HUCITEC, 2006, 87-111.

QUEIROZ, Sergio. Aprendizado tecnológico. Economia da inovação tecnológica. São Paulo: Editora da Ordem dos economistas do Brasil, 2006.

RIBEIRO, L. C. S. Ciclos sistêmicos de acumulação Arrighianos e a crise econômica de 2008: será o fim do ciclo norte-americano?. DIÁLOGO E INTERAÇÃO, V. 2, 2009. Disponível em: $<$ http://www.faccrei.edu.br/dialogoeinteracao>. Acesso em: 08 de dezembro de 2018.

ROBINSON, W. Giovanni Arrighi: Systemic Cycles of accumulation, Hegemonic Transitions and the Rise of China. In: New Political Economy, November, 2010.

ROSENBERG, Natham. Por dentro da caixa-preta: tecnologia e economia. Unicamp, 2006.

SALERNO, M. S.; MIRANDA, Z. Japão e as mudanças institucionais e políticas de C, T\&I. Agência Brasileira do Desenvolvimento Industrial. Brasília, v. 15, p. 282-311., 2010.

SCHUMPETER, J. A. A teoria do desenvolvimento econômico: uma investigação sobre lucros, capital, crédito, juro e o ciclo econômico. Tradução de Maria Sílvia Possas. 2. ed. São Paulo: Nova Cultural, 1985. 